\title{
Caracterização sedimentológica dos modelos deposicionais do reservatório de Cachoeira Dourada-GO/MG*
}

\author{
João Batista Pereira Cabral** \\ Luiz Alberto Fernandes ${ }^{* * *}$ \\ Valter Antonio Becegato \\ Sebastião Alves da Silva ${ }^{* * * * *}$
}

\section{Resumo}

A presente pesquisa teve por objetivo avaliar os modelos deposicionais existentes no reservatório de Cachoeira Dourada GO/MG. Foram avaliados vinte oito perfis verticais de sedimentos de fundo do lago cuja superfície é de $74 \mathrm{~km}^{2}$. Os métodos utilizados seguiram as propostas de Carvalho (1994) e Moris \& Fan (1996). Os modelos deposicionais identificados conforme análises de associações de fácies são: depósito de deltas - ocorrem nas áreas de desembocadura dos afluentes no lago; depósito de leito - do barramento ao córrego do Corgão e depósitos de correntes que ocorrem entre o córrego do Corgão e rio Piedade.

Palavras-chave: Sedimentos; Reservatório; Modelos deposicionais

\footnotetext{
* Parte da tese de doutorado do primeiro autor defendida em outubro de 2006 junto ao Programa de Pós-Graduação em Geologia Ambiental da UFPR.

Professor do Departamento de Geografia - UFGO - Campus Jataí (jbcabral2000@yahoo.com.br).

*** Professor do Departamento de Geologia UFPR (lufernandes@ufpr.br).

**** Professor do Departamento de Engenharia Ambiental - UDESC (becegaro@cav.udesc.br)

${ }^{* * * * *}$ Mestre em Geologia Ambiental - UFPR (silvaufg@yahoo.com.br).
}

Geosul, Florianópolis, v. 25, n. 50, p 175-198, jul./dez. 2010 
CABRAL, J.B.P. et al. Caracterização sedimentológica dos modelos ...

Sedimenthological characterization of the Cachoeira DouradaGO/MG reservoir's depositional models

\begin{abstract}
The present research has as objective to evaluate the existing depositional models in the Cachoeira Dourada reservoir -GO/MG. Twenty eight deep lake vertical profiles had been evaluated (the lake's deep area measures $74 \mathrm{Km}^{2}$ ). The used methods had followed the Carvalho (1994) and Morris \& Fan (1996) proposals. The depositional models identified facies associations are: deltas occurred in the lake's tributaries mouth areas; stream bed - from the slide bars to the Corgão stream; and stream deposits - occurred between the Corgão and the Piedade rivers.
\end{abstract}

Key words: Sediments; Reservoir; Depositional models.

\title{
Introdução
}

O aproveitamento da água para a geração de energia elétrica encontrou no território brasileiro um importante campo para o desenvolvimento e consolidação das UHEs (Usinas Hidrelétricas).

O conhecimento da quantidade de sedimentos transportados e depositados pelos rios é de fundamental importância para o planejamento e aproveitamento dos recursos hídricos de uma região, uma vez que os danos ambientais (assoreamento e eutrofização) causados pela deposição destes sedimentos dependem da quantidade e da natureza dos mesmos, as quais, por sua vez, dependem dos processos de erosão, transporte e deposição.

Dentre os problemas causados pela deposição de sedimentos nos lagos de usinas hidrelétricas, pode-se destacar o assoreamento, que altera a capacidade de armazenamento de água, diminuindo a vida útil do reservatório, provocando a necessidade de dragagens periódicas de alto custo. 
CABRAL, J.B.P. et al. Caracterização sedimentológica dos modelos ...

A retenção de material particulado no lago, pela redução no regime de fluxo, é inevitável, porém, o assoreamento é um processo passível de ser administrado e reduzido. Nas últimas décadas desenvolveram-se estudos relacionados ao assoreamento de reservatórios de usinas hidrelétricas, visando sua manutenção e redução de perda de vida útil.

$\mathrm{Na}$ atualidade, um grande número de reservatórios brasileiros se encontra total ou parcialmente assoreado, principalmente os de pequeno e médio porte. Isto acontece pelo fato de não se ter considerado o potencial de erosão nas bacias hidrográficas, nem os processos de sedimentação envolvidos, o que poderia atenuar a perda de vida útil dos reservatórios (CARVALHO, 2000; CARVALHO et al. 2000).

A caracterização sedimentológica e descrição dos depósitos de fundo foi aplicado em reservatórios brasileiros pela primeira vez no trabalho desenvolvido por Ponçano et al. (1981) e posteriormente empregado por Coelho (1993), Oliveira (1994), Rossato et al. (2002) e Saunitti (2003 e 2004).

Nesse tipo de pesquisa os referidos autores, posteriormente buscaram correlacionar o material amostrado no fundo de reservatórios com as prováveis áreas-fonte, mas não propuseram nenhum modelo de classificação de depósito, fácies e associações de fácies, na tentativa de se criar um método de análise de modelos deposicionais, que permita descrever a passagem de ambiente fluvial para lacustre, de acordo com os depósitos novos e antigos.

A escolha do reservatório de Cachoeira Dourada para avaliação dos modelos deposicionais vigentes deve-se ao fato de ser o menor em extensão e armazenamento de água no complexo de barragens construídas ao longo do rio Paranaíba, diminuindo e simplificando, portanto, o volume de trabalho. $\mathrm{O}$ mesmo situa-se a jusante dos reservatórios de Itumbiara e Emborcação. Tal escolha deve-se ainda, ao fato de constituir-se no único reservatório daquele rio que opera a fio d’água, cuja profundidade média é de $15 \mathrm{~m}$. 
CABRAL, J.B.P. et al. Caracterização sedimentológica dos modelos ...

Este trabalho objetiva caracterizar modelos
deposicionais que estão ocorrendo no reservatório de Cachoeira Dourada, baseando-se na proposta de Carvalho (1994, 2000) e por Morris \& Fan (1997).

\section{Localização da área de estudo e aspectos físicos da bacia hidrográfica}

A bacia hidrográfica do reservatório da Usina Hidrelétrica (UHE) de Cachoeira Dourada (GO/MG) corresponde ao trecho médio do rio Paranaíba, localizada na divisa entre os estados de Goiás e Minas Gerais. Situa-se entre as coordenadas de $7910000 \mathrm{~m}$ e $8040100 \mathrm{~m}$ de latitude Sul, e $650000 \mathrm{~m}$ e $750500 \mathrm{~m}$ de longitude W (Figura 1). 
CABRAL, J.B.P. et al. Caracterização sedimentológica dos modelos ...

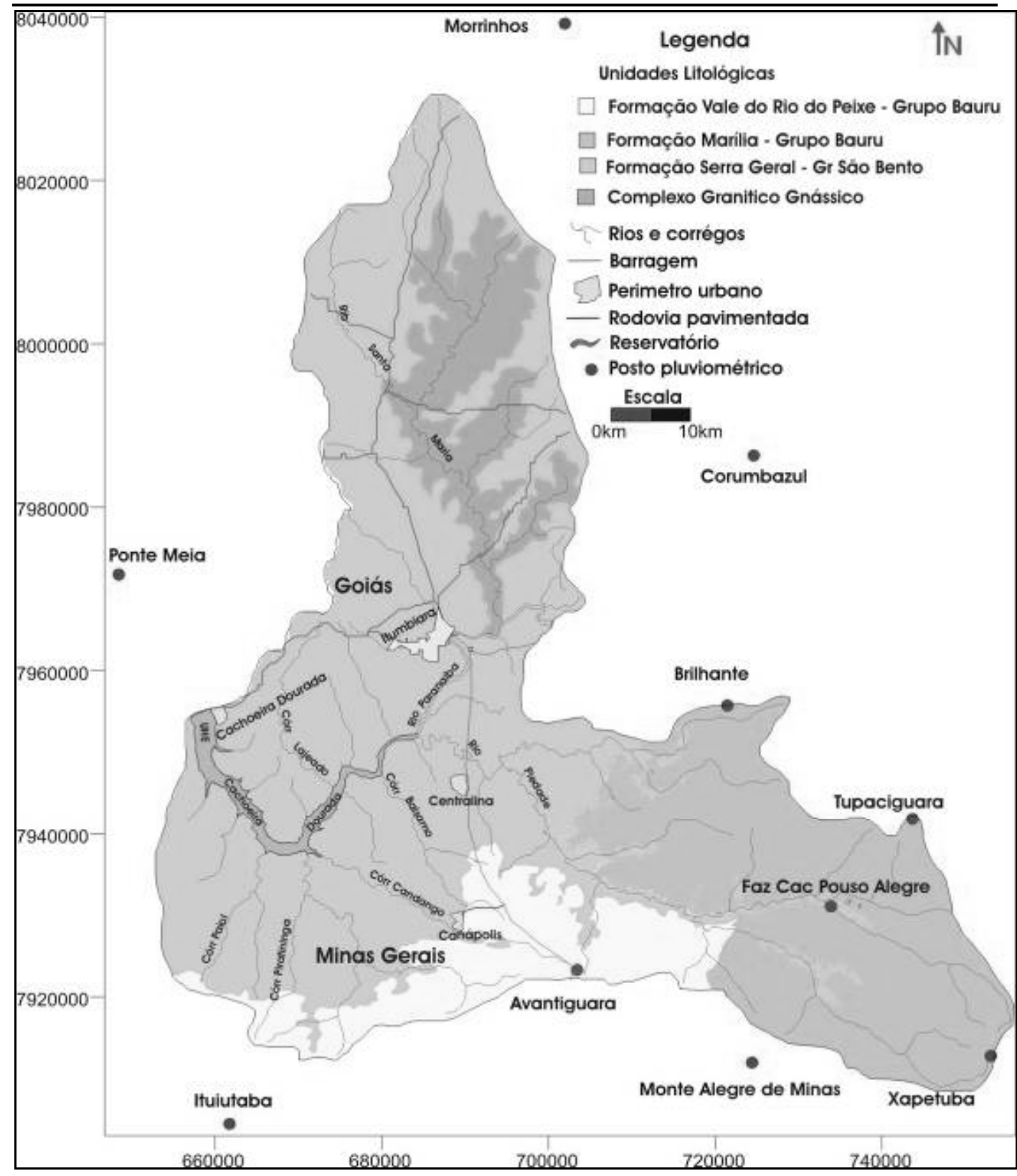

FIGURA 1. Mapa geológico da área de estudo, adaptado da Agência

Goiana de Indústria e Mineração/Companhia de Pesquisa de Recursos Minerais (AGIM/CPRM - 2002).

O reservatório foi construído em 1959, faz parte do complexo de barragens da bacia do rio Paranaíba, com a finalidade principal de gerar energia elétrica. Seu lago foi planejado para um 
CABRAL, J.B.P. et al. Caracterização sedimentológica dos modelos ...

volume total de $519 \times 10^{6} \mathrm{~m}^{3}$, cuja bacia de drenagem abrange uma área de $5.111 \mathrm{~km}^{2}$.

$\mathrm{Na}$ área de estudos predominam solos típicos de regiões tropicais, muito intemperizados, cujos cátions como cálcio e magnésio foram lixiviados ao longo dos perfis, caracterizando solos pobres de baixa fertilidade natural, representados pelo grupo dos Latossolos. O substrato da bacia hidrográfica é constituído por diversos tipos de rochas (Figura 1) e seus produtos de alteração como: basaltos da Formação Serra Geral (Cretáceo Inferior) do Grupo São Bento; arenitos das formações Vale do Rio do Peixe (FVRP) e Marília do Grupo Bauru, depositados no Cretáceo Superior; rochas graníticas e gnáissicas do embasamento arqueano.

O relevo é constituído por formas de dissecação tabulares e elevações de topo plano, com diferentes ordens de grandeza, formando um conjunto de feições complexas. As áreas com relevos residuais correspondem aos morros "testemunhos" areníticos da Formação Marília. Esses arenitos são agregados por cimento de carbonato de cálcio e/ou argilas, o que lhes conferem maior resistência em relação ao intemperismo e à erosão (IBGE 1983; LATRUBESSE, et al. 2004).

O clima dominante segundo a classificação de Köppen, é do tipo Cwa, ou seja, quente e úmido, com estação chuvosa no verão e seca no inverno, com temperatura média anual entre $22^{\circ} \mathrm{C}$ e $24^{\circ} \mathrm{C}$ e máxima podendo ultrapassar $35^{\circ} \mathrm{C}$. A precipitação anual oscila entre 1200 e $1600 \mathrm{~mm}$, cujo período chuvoso concentra-se entre outubro e abril. As médias mensais nesse período variam de 100 a $350 \mathrm{~mm}$, enquanto na estação seca (abril a setembro), o índice pluviométrico mensal varia de 0 a $100 \mathrm{~mm}$, caracterizando um período de deficiência hídrica e de temperaturas mais baixas (SCOPEL \& ASSUNÇÃO, 1999; SECTEC, 2000; CABRAL et al. 2005).

\section{Materiais e métodos}

A coleta de sedimentos de fundo foi efetuada com amostrador tipo CLS (Figura 2) que é uma adaptação do modelo 
CABRAL, J.B.P. et al. Caracterização sedimentológica dos modelos ...

Piston Core para obtenção de testemunhos em colunas verticais, por cravação de um tubo de PVC (50 mm de diâmetro por 50 a 150 cm de comprimento) no fundo do reservatório, conformes técnicas apresentadas por Ponçano et al. 1981. A amostragem foi executada por um mergulhador (Figura 3). Depois de cravado, o tubo foi fechado, ainda no fundo, antes de ser alçado ao barco.

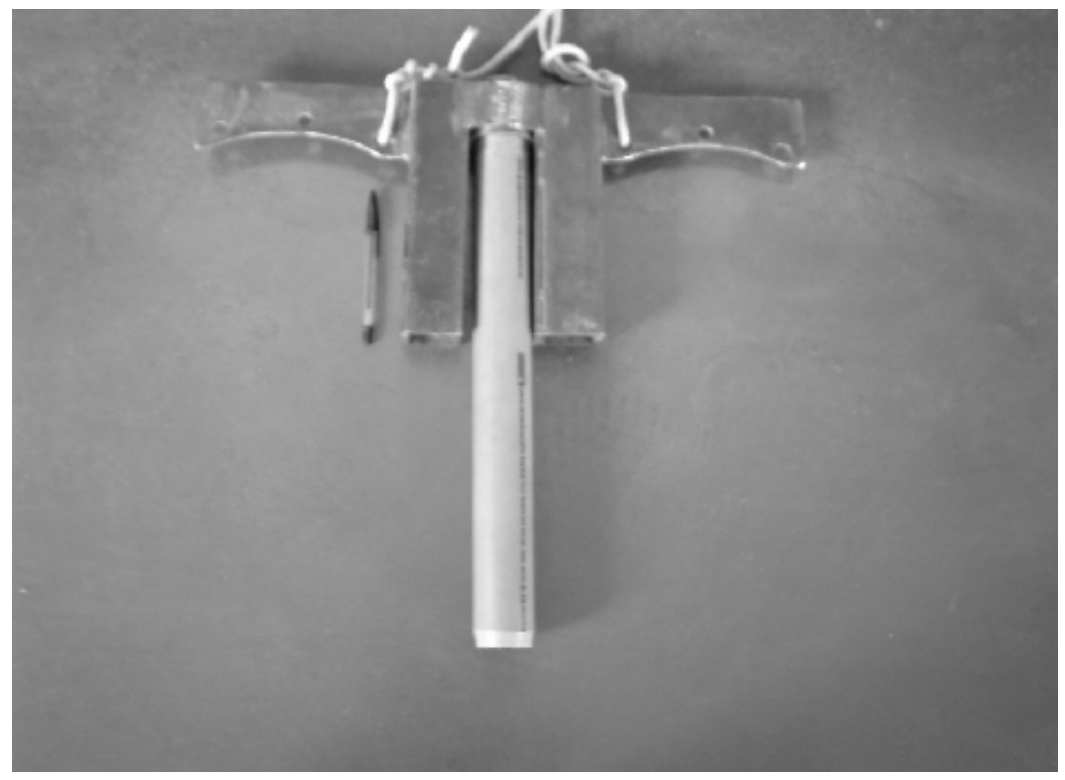

FIGURA 2: Amostrador, adaptado do modelo Piston Core preparado para obtenção de testemunhos verticais.

As amostras de sedimentos dos vinte e oito perfis verticais foram analisadas com uma lupa e descritas segundo os seguintes parâmetros: cor, granulação, textura, seleção, composição mineralógica, estruturas sedimentares, uso de escala granulométrica de bolso do laboratório de sedimentologia (Labsed) da UFPR, conforme a escala de Wentworth (1922), sendo os modelos deposicionais adaptados das propostas feita por, Carvalho (1994, 2000), Morris e Fan (1997). 
CABRAL, J.B.P. et al. Caracterização sedimentológica dos modelos ...

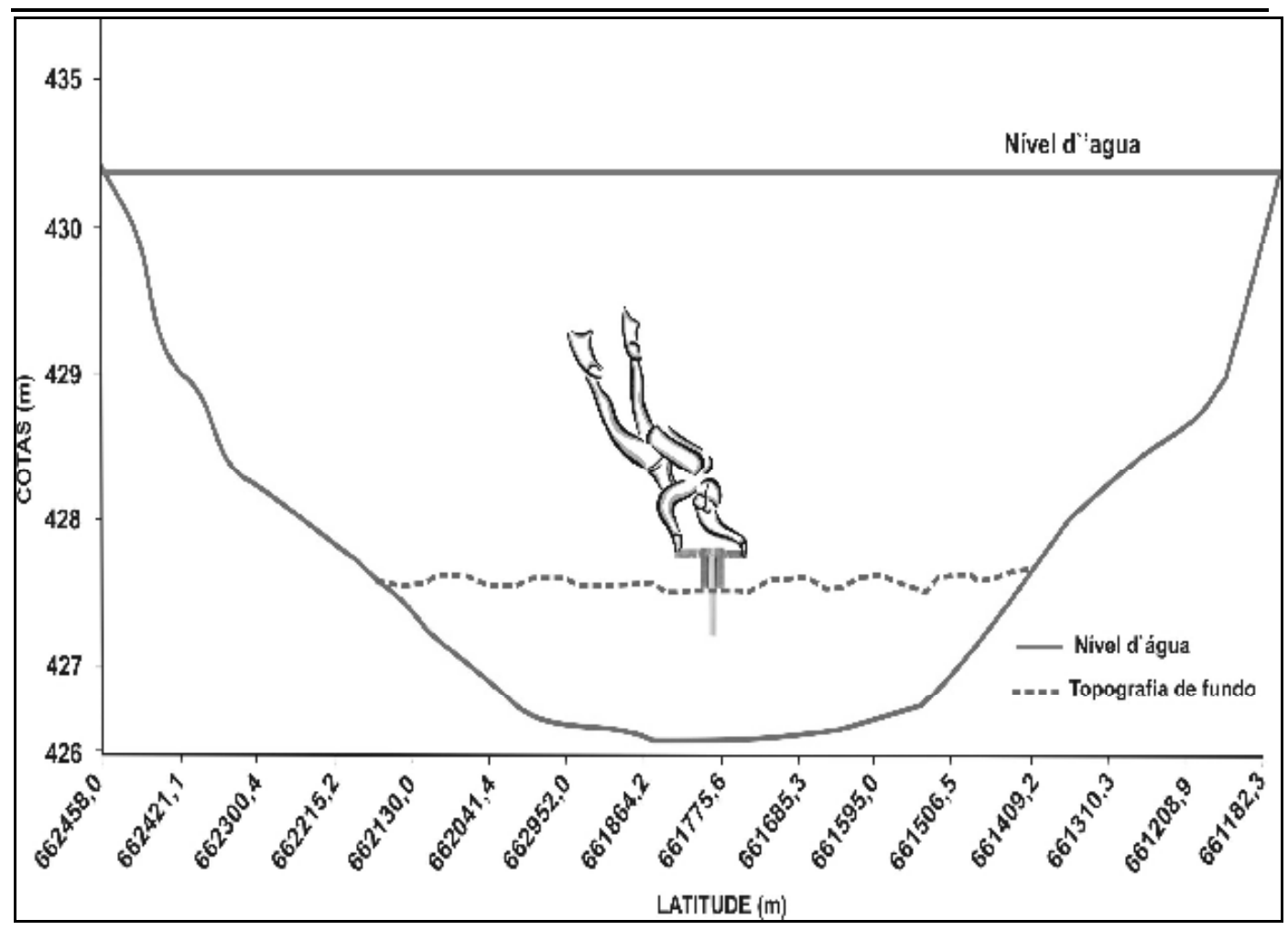

FIGURA 3: Croqui esquemático de como foram obtidos os perfis verticais da seqüência depositada.

A partir das análises dos possíveis processos de sedimentação interpretados, foram estabelecidos três modelos deposicionais, denominadas de acordo com o ambiente de formação, baseado nas propostas de Carvalho (1994, 2000), Morris e Fan (1997), e interpretados como correspondente a: depósito de leito, delta e corrente.

A) Depósito de Leito: Neste tipo de depósito o material sedimentado é predominantemente argiloso/siltoso. Pode ocorrer a presença de estratos de areia muito fina a fina depositado abaixo do material argiloso/siltoso.

B) Depósito de Corrente: Neste tipo de depósito o material sedimentado é predominantemente arenoso, podendo apresentar lentes de argila e silte. 
CABRAL, J.B.P. et al. Caracterização sedimentológica dos modelos ...

C) Depósito de Delta: é o resultado da acumulação dos sedimentos grossos e finos (podendo ser em extratos ou lentes) devido à pequena declividade dos afluentes e, consequentemente, pequena capacidade de descarga de água, o que favorece o acúmulo de areia, silte e argila na foz.

\section{Discussão dos dados}

A descrição de cada perfil vertical foi feita por comparação visual, com uso de escala granulométrica de Wentworth (1922). A análise dos testemunhos, apesar de não fornecer um registro contínuo de toda seqüência sedimentar no fundo do lago, permitiu a obtenção de dados básicos necessários à investigação da estratigrafia da parte superior dos depósitos e possível evolução dos processos de assoreamento que vêm ocorrendo no reservatório.

Após a descrição dos perfis verticais, estes foram agrupados, cujas características e inter-relações permitiram interpretar o ambiente de sedimentação do reservatório de Cachoeira Dourada conforme a proposta de Carvalho $(1994,2000)$ e de Morris e fan (1997). Tais associações foram denominadas de acordo com o ambiente atual de formação e identificadas em depósitos.

\section{Depósito de leito}

A partir da comparação dos perfis topográficos das fases anterior e posterior ao enchimento do reservatório e análise dos perfis verticais (figura 4) foi possível identificar um decréscimo ascendente na granulometria desde areia muito fina a material silteargiloso nos perfis $1 \mathrm{~A}$ a $1 \mathrm{E}, 2$ e $3 \mathrm{D}$. 
CABRAL, J.B.P. et al. Caracterização sedimentológica dos modelos ...

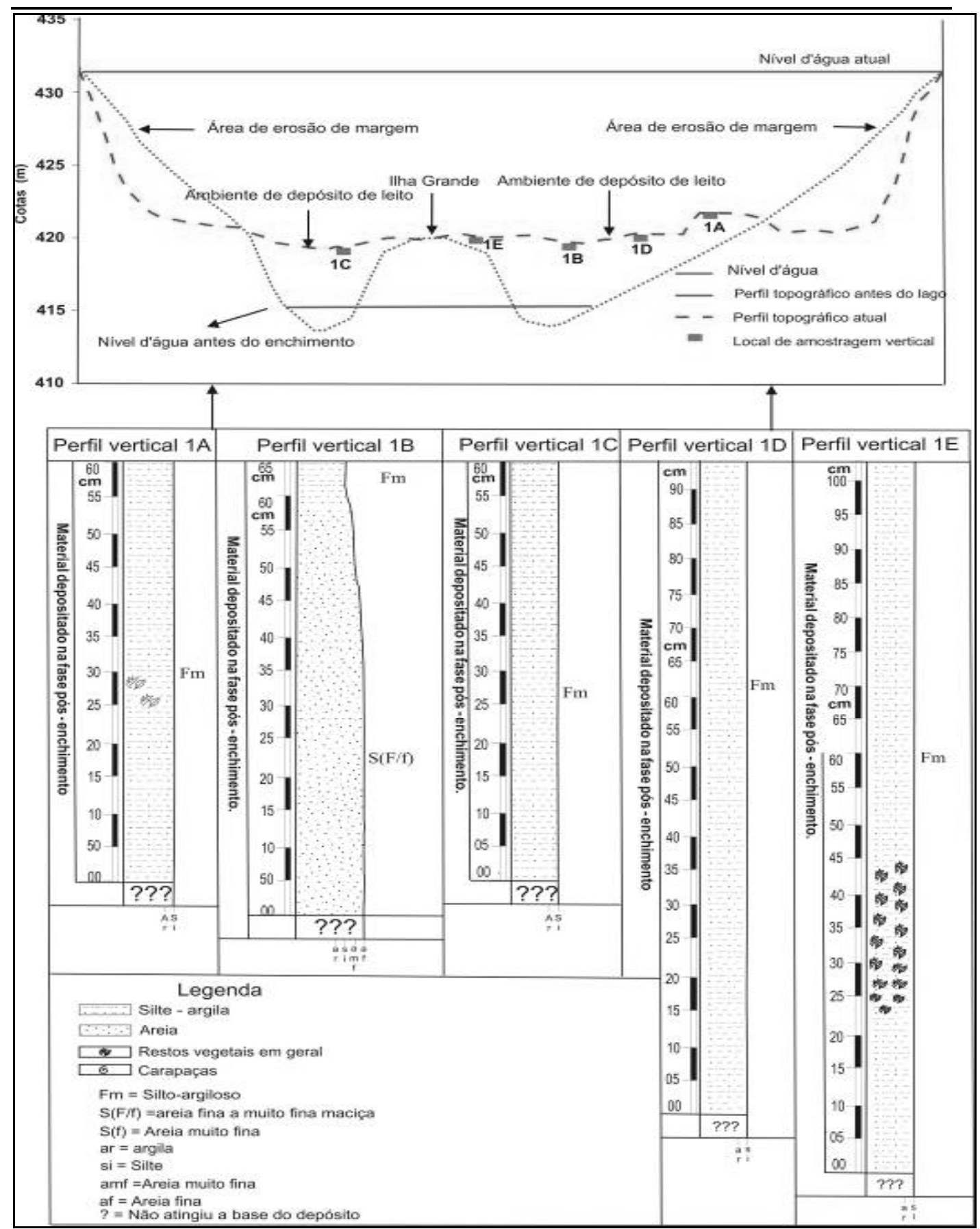

FIGURA 4: Perfil topográfico com indicação de erosão lateral nas margens, processo de sedimentação junto à antiga ilha Grande e associações de fácies da seção transversal 3. 
CABRAL, J.B.P. et al. Caracterização sedimentológica dos modelos ...

Neste tipo de depósito o material sedimentando é predominantemente argilo/siltoso. Pode ocorrer a presença de estratos de areia muito fina a fina depositados abaixo do material argilo/siltoso, que é a fácies característica deste sub-ambiente.

Este tipo de material de acordo com a proposta de Carvalho (1994), Morris e Fan (1997) são representativos de depósito de leito, pois as partículas de silte e argila são geralmente transportadas para longe dos deltas e depositadas no trecho mais baixo do reservatório.

A deposição do material fino no reservatório se dá por decantação devido ao barramento da água, ao aumento da seção transversal, à diminuição da velocidade de escoamento da água, à estabilização da vazão, à eficiência de retenção e à velocidade de queda das partículas (Brune, 1953). O possível modelo deposicional esquemático para este sub-ambiente é apresentado na Figura 5 A e B. 
CABRAL, J.B.P. et al. Caracterização sedimentológica dos modelos ...

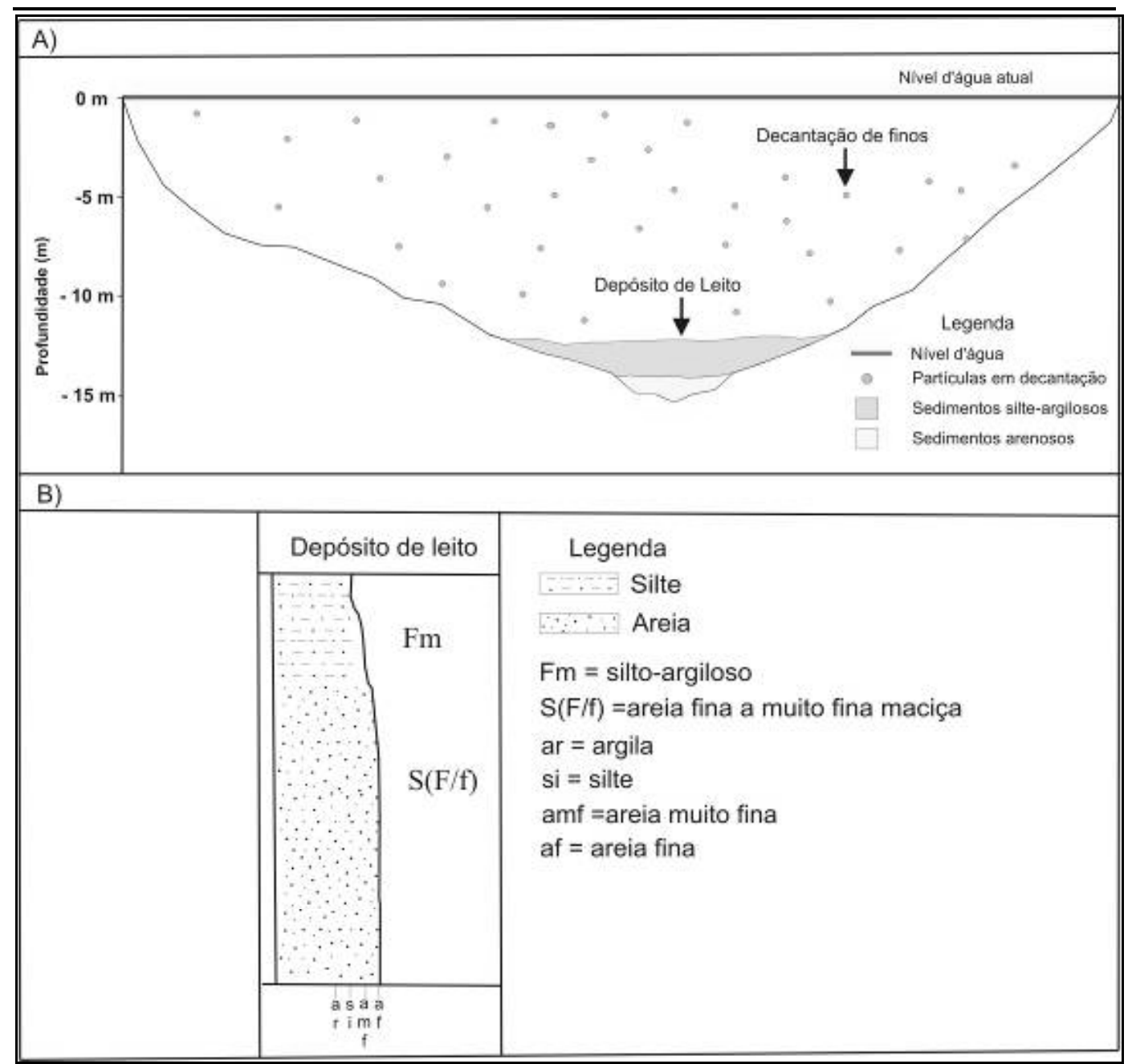

FIGURA 5: A) Croqui esquemático da seqüência deposicional no ambiente leito, B) seção vertical para o depósito de leito.

\section{Depósito de corrente}

As fácies características da passagem de um ambiente de alta energia para um de baixa energia são representadas com a deposição de material de granulação grossa a muito fina. Os perfis verticais que apresentam características da passagem de um ambiente de baixa energia para alta energia foram verificadas nos perfis 3A, 3B, 4A, 5, 6, 7 (os três últimos naFigura 6), 8C, 9B, $10 \mathrm{~B}, 11,13 \mathrm{~A}, 14,15$ e 17 . Neste tipo de depósito a carga arenosa é depositada por processos episódicos de grande energia e também 
CABRAL, J.B.P. et al. Caracterização sedimentológica dos modelos ... fluxos oscilatórios, que resultaram em corpos tanto maciços como estratificados.

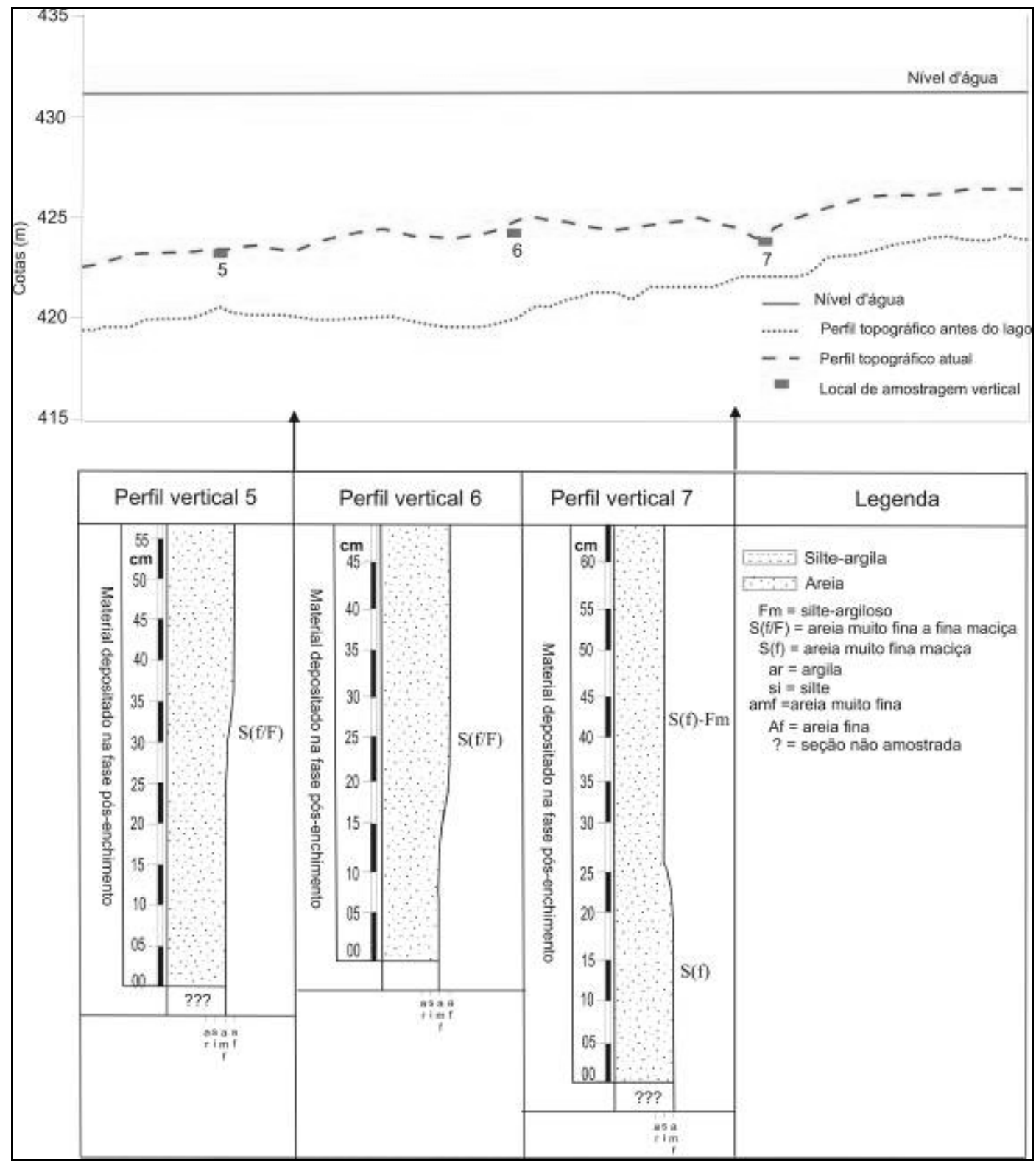

FIGURA 6: Perfil topográfico com indicação da sedimentação ocorrida entre o córrego do Paiol e Flecha, e associações de fácies da seção longitudinal.

A partir das descrições dos perfis verticais deste subambiente (depósito de corrente), as fácies desta associação podem 
CABRAL, J.B.P. et al. Caracterização sedimentológica dos modelos ...

ser consideradas correspondentes a depósitos de regime de escoamento superior, conforme a concepção de Simons et al. (1965). Este regime se caracteriza por baixa resistência ao escoamento e transporte intenso de sedimentos. O possível modelo deposicional esquemático para este sub-ambiente é apresentado na Figura 7 A e B.

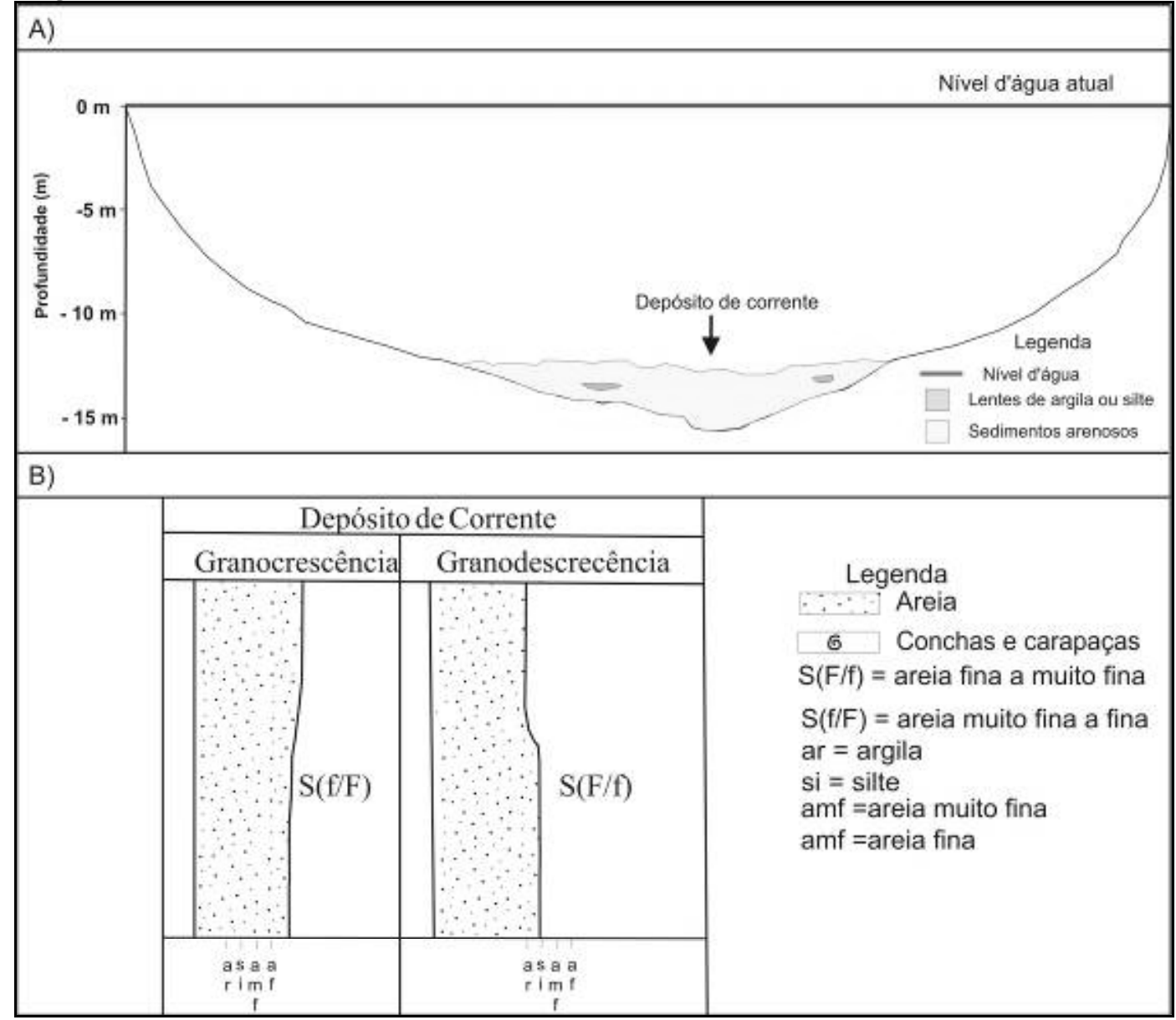

FIGURA 7: A) Croqui esquemático do perfil vertical dos depósitos do ambiente de corrente e B) seção colunar para o depósito de corrente apresentando granocrescência e granodecrescência da base para o topo. 
CABRAL, J.B.P. et al. Caracterização sedimentológica dos modelos ...

\section{Depósito de delta}

Depósitos de deltas ocorrem em áreas de encontro dos cursos fluviais dos afluentes que desembocam no lago ou reservatório. A sedimentação ocorre devido à diminuição da velocidade de escoamento da água, aumento da seção transversal, regularização da vazão e efíciência de retenção do reservatório.

Em Cachoeira Dourada os depósitos de delta, de acordo com os perfis verticais e análises dos materiais depositados nos testemunhos verticais amostrados entre os pontos 8A, 9A e 10A (Figura 8), são compostos por materiais silte-argilosos e arenosos.

A partir das análises dos perfis verticais e fácies características, para este tipo de depósito em Cachoeira Dourada, verificou-se uma variação granulométrica em decorrência das diferentes áreas-fonte, das oscilações no fluxo de escoamento das águas dos afluentes que atingem o reservatório, e aos diferentes índices de precipitações e da ação antrópica que ocorrem nas bacias hidrográficas afluentes.

A associação de fácies para este modelo de depósito está mais relacionada a ambientes encontrados na desembocadura de rios com o lago. A deposição dos sedimentos ocorre a partir de partículas que se movem por arraste e pequena fração de materiais em suspensão. Partículas como argilas e silte de diâmetros menores, depositam-se mais lentamente, diferentemente das areias que são mais densas e depositadas mais rapidamente.

No modelo deposicional de Cachoeira Dourada (Figura 9 A e B) as camadas de topo apresentam características essencialmente fluviais com predomínio de material arenoso, que são os primeiros a se depositar ao entrar no reservatório, enquanto que as camadas frontais apresentam características mistas "flúvio-lacustres". 
CABRAL, J.B.P. et al. Caracterização sedimentológica dos modelos ...

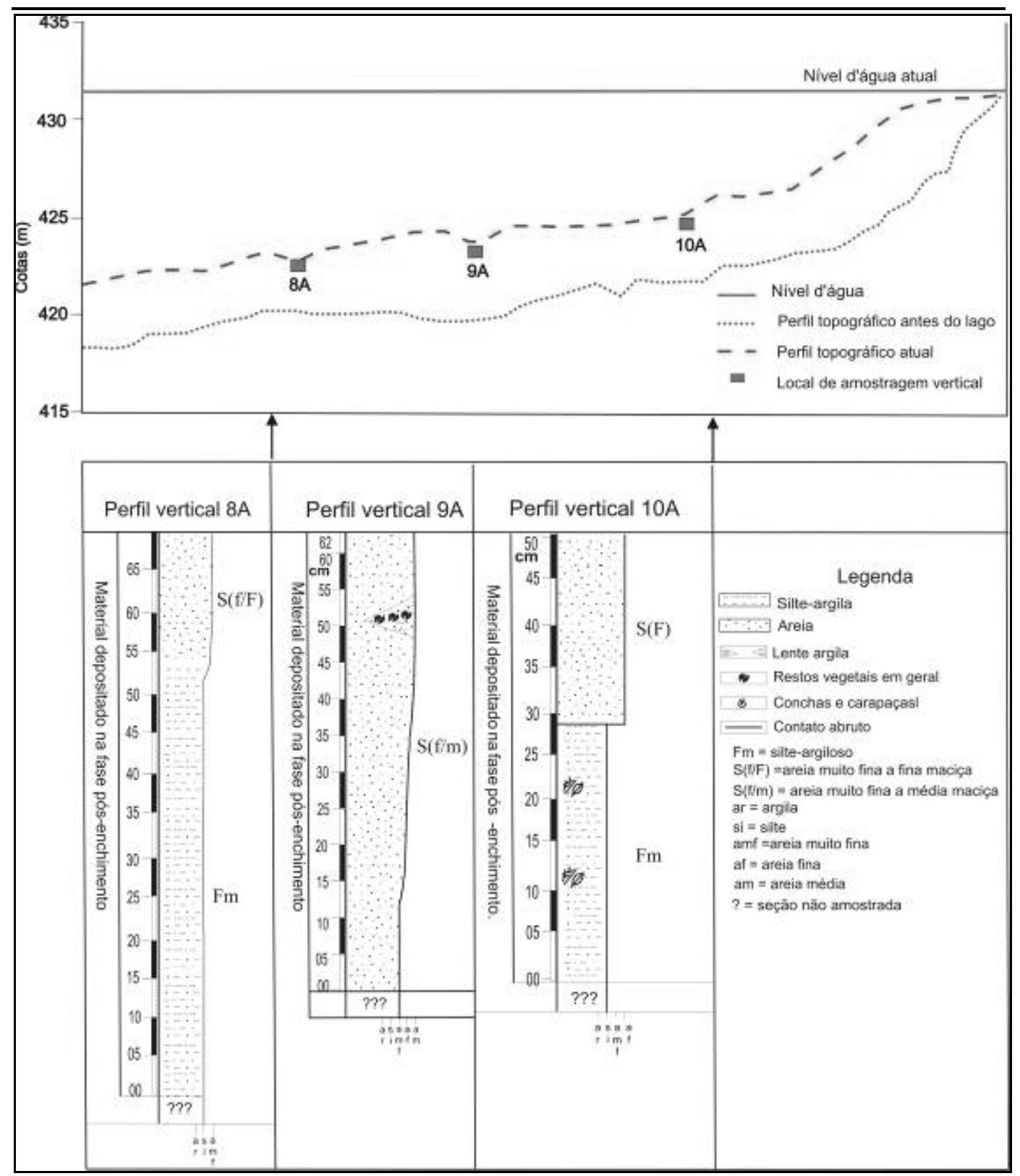

FIGURA 8: Perfil topográfico com indicação da sedimentação entre ribeirão Piratininga ao córrego do Paiol e associações de fácies da seção transversal 24. 
CABRAL, J.B.P. et al. Caracterização sedimentológica dos modelos ...

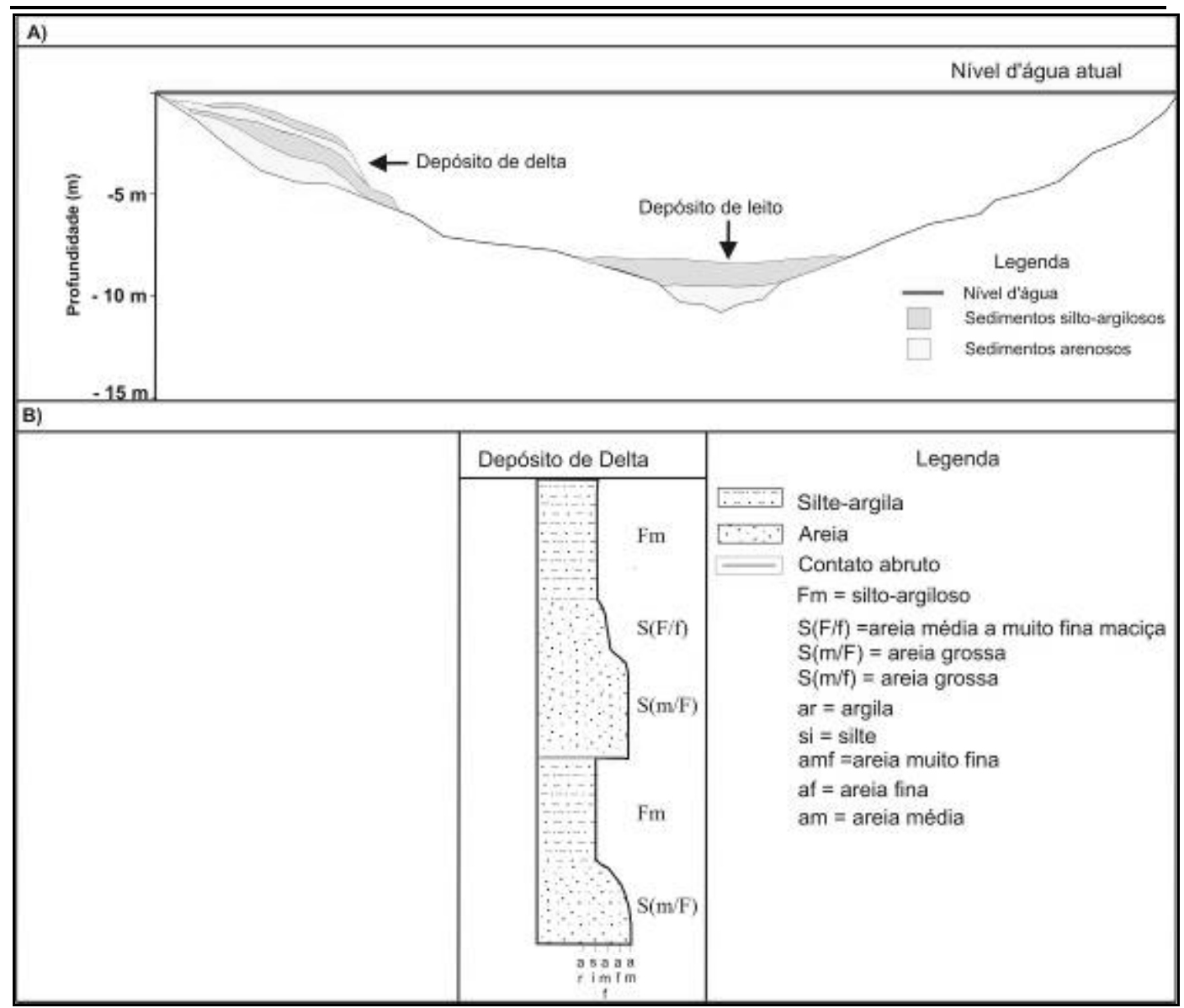

FIGURA 9: A) Croqui esquemático do processo de sedimentação no ambiente de delta e B) seção colunar para o ambiente delta.

\section{Análise geral dos modelos deposicionais do reservatório}

Não se observou depósito de remanso constituído em princípio de materiais de maior granulação, como seixos e areia grossa. Segundo Carvalho (2000) tais depósitos podem progredir tanto para dentro do lago quanto para montante, pois na medida depósito cresce, o efeito de remanso se estende, podendo obstruir a seção do canal, resultar em elevação de níveis de assoreamento a montante podendo provocar enchentes. 
CABRAL, J.B.P. et al. Caracterização sedimentológica dos modelos ...

Para se compreender a distribuição espacial dos possíveis modelos deposicionais (Figura 10) atuantes no reservatório de Cachoeira Dourada, foi gerado um mapa esquemático (pelo método do inverso da distância no programa Surfer 8.0) a partir da análise e descrição dos 28 perfis verticais.

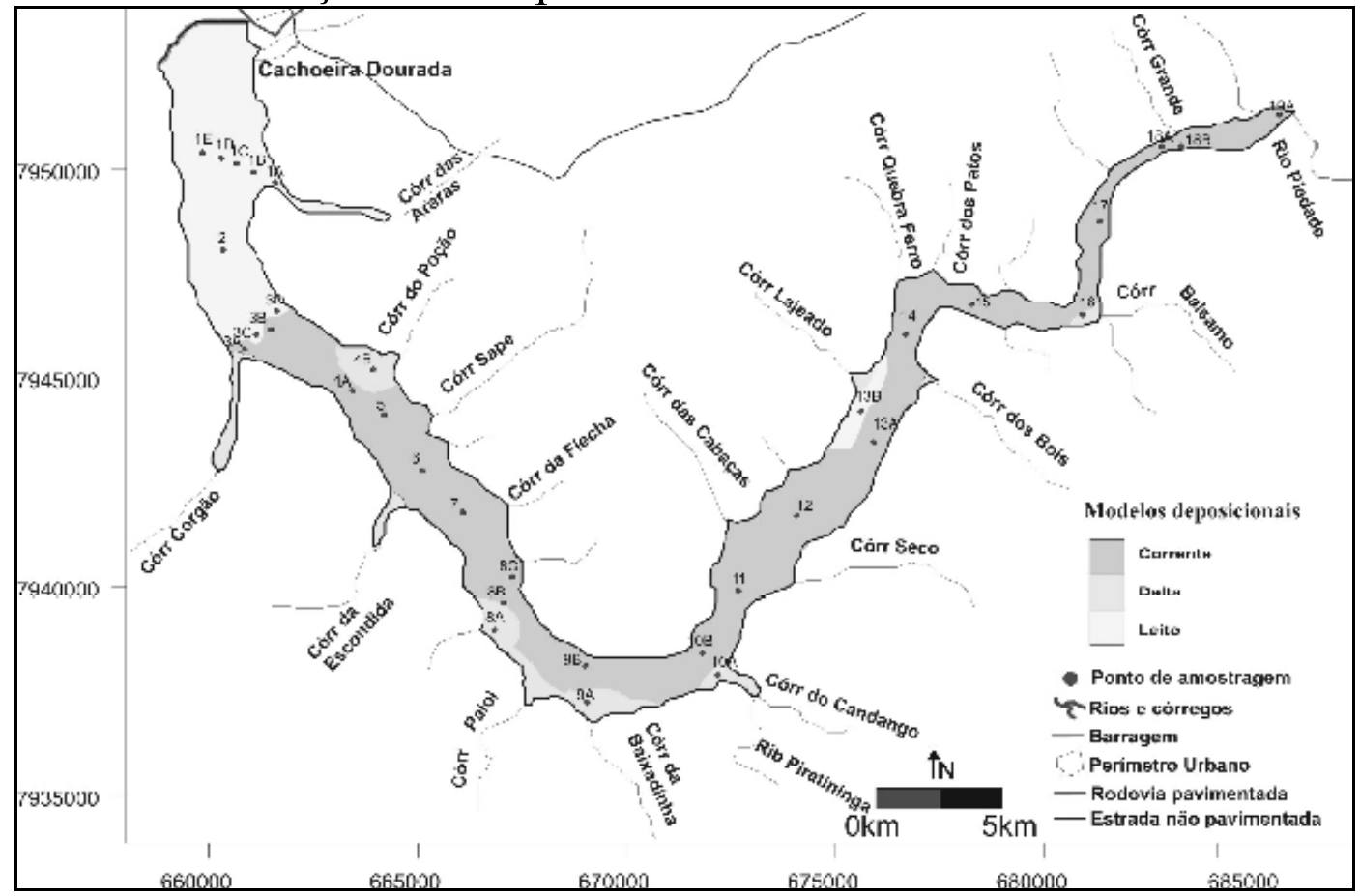

FIGURA 10: Mapa esquemático de distribuição dos tipos de depósitos de assoreamento do reservatório de Cachoeira Dourada - GO/MG.

A partir da análise do mapa é possível verificar que entre o barramento e o córrego do Corgão ocorre predomínio de depósito de leito, composto por pelitos (fácies silte-argilosas), sempre sobrepostos às fácies de areia fina a muito fina.

No modelo deposicional de Carvalho (1994, 2000) a deposição dos sedimentos silto-argiloso sobre arenosos refletem as modificações ocorridas após o represamento da água, uma vez que ocorre um aumento da seção transversal, a velocidade de escoamento da água diminui, -a vazão estabiliza a eficiência de retenção e a velocidade de caimento das partículas modificam-se. 
CABRAL, J.B.P. et al. Caracterização sedimentológica dos modelos ...

O depósito de delta foi verificado sempre no encontro dos afluentes com o reservatório, ocasionado em virtude do avanço do regime fluvial dos afluentes para o interior do reservatório. As associações de fácies correspondentes a estes depósitos podem ser consideradas complexas, pois o sistema deposicional deltaico é reconhecido pela intercalação de sedimentos arenosos e pelíticos, com estruturas sedimentares maciças.

A base do sistema deposicional deltaico para o reservatório de Cachoeira Dourada na região de abrangência dos córregos do Poção (perfil vertical 4B) e Bálsamo (perfil vertical 16) consistem de material arenoso e parecem indicar uma oscilação do fluxo de alta e baixa energia. A partir da análise do transecto entre os perfis verticais $8 \mathrm{~A}, 9 \mathrm{~A}$ e $10 \mathrm{~A}$, mais respectivamente na desembocadura do córrego da Baixadinha e Candando/Piratininga, a base dos mesmos é pelítica, enquanto os arenitos do topo têm granulação desde muito fina a fina, indicando que havia uma energia alta, que foi diminuindo ao adentrar no reservatório.

O depósito de corrente situa-se entre o córrego do Corgão e o rio Piedade (Figura 10). Neste ambiente ocorre o predomínio de depósitos arenosos associados ao fluxo de regime alto e baixa energia. Constitui-se principalmente de areia, com algumas intercalações de sedimentos de granulação fina (silte).

No primeiro setor entre os córregos do Corgão e do Candango, ocorre o predomínio da fração de areia muito fina e areia média; esses locais apresentam granocrescência (perfis 3A, 5, 6 e 9B) e granodecrescência (perfis 3B, 7, 8C e 10B). $\mathrm{Na}$ deposição de sedimentos desta associação, predominaram possivelmente processos de fluxos oscilatórios. Essa é a principal área de aporte de sedimentos arenosos oriundos dos solos e da Formação Vale do Rio do Peixe carreado pelo córrego do Candango/ribeirão Piratininga.

Entre o córrego das Cabaças e o rio Piedade, a fácies arenosa varia de areia muito fina a areia grossa. Neste setor a granulometria dos sedimentos depositados indica possíveis oscilações, representando, assim, eventos de alta e baixa energia. 
CABRAL, J.B.P. et al. Caracterização sedimentológica dos modelos ...

No geral a associação de fácies nesse ambiente constitui o maior volume dos depósitos, permitindo inferir maior disponibilidade de carga arenosa em relação à fina depositada por processos episódicos de grande energia, permitindo fácies de areias com estratificações cruzadas e com possível gradação normal.

Na proposta de Morris e Fan (1997) os depósitos de corrente podem ser associados com maior fornecimento de sedimentos finos, que ocorrem nas áreas de depósito de leito. Em Carvalho (1994, 2000), não foi verificado nenhum tipo de comentário sobre a possibilidade da existência desse modelo em seus trabalhos. Os depósitos de areia em reservatórios são algumas vezes associados de acordo com o método de Carvalho $(1994,2000)$ a depósitos de margem, devido ao processo de desmoronamento das bordas dos reservatórios, sem ser feita nenhuma associação a áreas-fonte existentes a montante.

A partir de uma análise crítica das fácies e associações de fácies do reservatório de Cachoeira Dourada, é possível verificar que, na caracterização do modelo deposicionais dos trabalhos desenvolvidos por Carvalho $(1994,2000)$ e por Morris e Fan (1997), o processo de sedimentação em reservatórios é tratado pelos seus aspectos hidráulicos e como um fator de avaliação do tempo de vida útil.

Os dados para análise do processo de sedimentação são obtidos principalmente de estações fluviométricas, pluviométricas e da bacia hidrográfica, gerando modelos empíricos sobre o processo de assoreamento em reservatórios, sem a discussão de um sistema deposicional lacustre que compreenda e explique os depósitos existentes conforme as possíveis áreas-fonte.

Quanto à evolução da sedimentação no reservatório, o lago da usina hidrelétrica de Cachoeira Dourada, pode ser classificado conforme os estágios de evolução proposto por Morris e Fan (1997), como de quase-equilíbrio, ocorrendo a transição de deposição contínua para um regime misto de deposição e erosão. $\mathrm{O}$ material sedimentado no lago pode ser considerado como um depósito afunilado, conforme a configuração longitudinal dos 
CABRAL, J.B.P. et al. Caracterização sedimentológica dos modelos ...

depósitos, pois o material particulado depositado é formado por sedimentos finos na direção da barragem $\mathrm{e}$ arenosos nas desembocaduras dos afluentes com o reservatório e nas regiões mais a momtante da barragem.

De um modo geral, é possível perceber que existe a necessidade de se correlacionar as modificações ocorridas no ambiental fluvial para lacustre, o que pode ser feito a partir da busca de conhecimento e aprofundamento das propostas de Miall (1996), Carvalho (1994 e 2000) e Morris e Fan (1997).

Face às lacunas verificadas nos modelos deposicionais e nos métodos de investigação de assoreamento de reservatório e partir de uma avaliação crítica das pesquisas realizadas por Ponçano et al. (1981), Coelho (1993), Oliveira (1994), Rossato (2002) e Saunitti (2003), juntamente com as análises dos perfis verticais (testemunhos) e associações de fácies verificadas para o reservatório de Cachoeira Dourada, a diferença da classificação de fácies de ambiente lacustre em relação à proposta inicial de Miall (1996) é fruto da própria dinâmica do meio e peculiar ao exemplo estudado, podendo ser utilizada em levantamentos posteriores no próprio reservatório ou em outros que apresentem características semelhantes.

Os possíveis modelos deposicionais verificados para Cachoeira Dourada indicam que aqueles existentes nas literaturas para a compreensão do processo de sedimentação em reservatórios devem ser empregados para se analisar setores de uma barragem, mas não a sua totalidade (toda a extensão) como se o reservatório fosse um único corpo, pois existe a necessidade do conhecimento dos processos históricos e atuais que permita analisar e avaliar a evolução do processo deposicional fluvial para o ambiente lacustre e apresentar expectativas do tempo de vida útil com maior acuracidade.

\section{Conclusões}

O material coletado na superfície de fundo é constituído principalmente por silte e argila, no setor entre o barramento e o córrego do Corgão. Entre os córregos do Corgão e da Flecha foi 
CABRAL, J.B.P. et al. Caracterização sedimentológica dos modelos ...

verificada a deposição de silte grosso a areia fina. As areias finas a muito finas são carreadas até o córrego do Corgão devido à energia de fluxo existente no local. O material de granulação mais grossa (areia média a grossa) é depositado principalmente na desembocadura do rio Piedade. Entre os córregos do Paiol e do Candango localiza-se a principal área de aporte de material arenoso fino a muito fino e pobremente selecionado. A distância das áreasfonte em relação ao reservatório não é suficiente para que os sedimentos cheguem a atingir melhor seleção, indicando que os mesmos são poucos retrabalhados.

Nos perfis verticais, observou-se que há predomínio de material silto-argiloso entre a barragem e o córrego do Corgão. Materiais silte-argilosos e arenosos (areia fina e muito fina) encontram-se entre os córregos do Corgão e da Flecha e dos córregos do Candango ao do Bálsamo. Com relação ao material arenoso, a deposição ocorre predominantemente entre os córregos do Paiol, do Candango (areia fina) e do córrego do Bálsamo ao rio Piedade (areia fina a grossa).

Os modelos deposicionais identificados no reservatório de Cachoeira Dourada conforme análises de associações de fácies são: 1) depósito de delta: ocorrem nas áreas de desembocadura dos afluentes no lago; 2) depósito de leito: do barramento ao córrego do Corgão e 3) depósito de corrente: ocorrem no antigo leito principal do rio Paranaíba entre o córrego do Corgão e rio Piedade.

\section{Referências bibliográficas}

Agência Goiana de Indústria e Mineração/Companhia de Recurso Minerais (AGIM/CPRM). Mapa geológico do estado de Goiás. CD-ROM. 2002.

BRUNE, G. - "Trap Efficiency of Reservoirs". Transactions American Geophysical Union, N34, 3, Junho. 407-418p. 1953. 
CABRAL, J.B.P. et al. Caracterização sedimentológica dos modelos ...

Carvalho, N.O. Hidrossedimentologia Prática. CPRM e ELETROBRÁS. Rio de Janeiro, RJ. 384p. 1994.

Carvalho, N.O. assoreamento de reservatórios - conseqüências e mitigação dos efeitos. In: IV Encontro Nacional de engenharia de Sedimentos. Santa Maria-RS. Cdrom. 1-22p. 2000.

Carvalho, N. O; Filizola Jr., Santos, P. M. C; Lima, J. E. F. W. Guia de avaliação de assoreamento de reservatórios. Brasília : ANEEL, 132p. 2000.

Coelho,M.P. Análise do processo de assoreamento do reservatório de Americana - SP. Dissertação de Mestrado em Geociências e Meio Ambiente. Programa de Pós-Graduação em Geociências. Universidade Estadual Paulista. Campus de Rio Claro. 69p. 1993.

Golden Software: SURFER, versão 8.0. conjunto de programas. 1CD-Rom e manuais. (informações em http://www.goldemsoftware.com). 1999.

Miall, A.D. Principles of Sedimentary Basin Analysis, SpringerVerlag, New York, 668p. 1996.

Morris, G.L; Fan, J. Reservoir sedimentation handbook: design and management of dams, reservoir, and watersheds for sustainable use. New York, McGraw-Hill. 805p. 1997.

Oliveira, A.M.S. Depósitos tecnogênicos e assoreamento de reservatórios. Exemplo do reservatório de Capivari, rio Paranapanema, SP / PR. Tese de Doutorado em Geografia Física. Programa de Pós-Graduação em Geografia. Universidade de São Paulo. 211p. 1994. 
CABRAL, J.B.P. et al. Caracterização sedimentológica dos modelos ...

Ponçano, W.L.;Gimenes, A.F.; Leite,A.A.G.; Carlstron Filho, C; Pradini, F.L.; Melo, M.S.de. - Metodologia para estudo de assoreamento de reservatório (III): roteiro para estudo de reservatórios no sul e sudeste brasileiro. In: CBGE, 3, Itapema (SC), anais, São Paulo, ABGE, V2. 331-353p. 1981.

Rossato, M.S; Basso,L.A; Suertegaray, D.M.A. Formação de depósitos tecnogênicos em barragens. $O$ caso da Lomba do Sabão, Rio Grande do Sul, Brasil. In: Revista Bibliográfica De Geografía Y Ciencias Sociales. Universidad de Barcelona. ISSN: 1138-9796.Vol. VII, N407. 2002.

Saunitti, R,M. Estudo sobre sedimentação no reservatório da barragem do rio Passaúna, Dissertação de mestrado em Geologia. UFPR. 120p. 2003.

Saunitti, R.M; Fernandes, L.A; Bittencourt, A,V.L. Estudo do assoreamento do reservatório da barragem do rio Passaúna Curitiba -PR, In: Boletim Paranaense de Geociências. N54 . 6582p. 2004.

Simons, D. B., RichardsoN, E.V., and Nordin, Jr. C.F. Sedimentary structures generated by flow in alluvial channels. In: Middleton, G.V., ed., Primary sedimentary structures and their hydrodynamic interpretation: SEPM Special Publication 12, p. 3452.1965 .

Wentworth,C.K. A scale of grade and class terms for clastic sediments. Journal of Geology.30: 377-392p. 1922.

Recebido em dezembro de 2010

Aceito em abril de 2010 